Research Article

\title{
Effects of Graphene Oxide Dispersion on Salt-Freezing Resistance of Concrete
}

\author{
Yihong $X u$ iD ${ }^{1,2}$ and Yingfang Fan ${ }^{2}$ \\ ${ }^{1}$ Institute of Road and Bridge Engineering, Dalian Maritime University, Dalian, China \\ ${ }^{2}$ Road and Bridge Engineering, Liaoning Provincial College of Communications, Shenyang, China
}

Correspondence should be addressed to Yihong Xu; sinx912@163.com

Received 25 July 2019; Revised 23 January 2020; Accepted 12 February 2020; Published 7 May 2020

Academic Editor: Marino Lavorgna

Copyright (c) 2020 Yihong Xu and Yingfang Fan. This is an open access article distributed under the Creative Commons Attribution License, which permits unrestricted use, distribution, and reproduction in any medium, provided the original work is properly cited.

\begin{abstract}
In order to study the effects of different amounts of graphene oxide dispersion on the salt-freezing resistance of concrete, graphene oxide lamellar dispersion with a concentration of $5 \mathrm{mg} / \mathrm{ml}$ was prepared by the improved Hummers' method and the ultrasonic dispersion method. Graphene oxide (GO) was characterized by Fourier-transform infrared spectroscopy (FTIR) and X-ray diffraction (XRD). The mechanical properties and durability of the salt-frozen concrete with different GO contents were examined, and its salt-freezing resistance mechanism was analyzed by microscopic tests. With the increasing salt-freezing time, the deterioration of GO concrete occurred under a combination of different modes, such as mortar shedding, microcrack propagation, denudation, and massive shedding. The optimum content of GO was detected as $0.03 \%$. In comparison to the reference specimen, the compressive strength of GO concrete increased by $34.83 \%$ after 200 salt-freezing cycles, and consequently loss rate and dynamic elastic modulus were found to be the smallest. The microscopic test results revealed the optimum GO content promoted the hydration of cement, regulated its microstructure, effectively hindered the destruction of concrete micromorphology during salt-freezing, and slowed down the initiation and propagation of internal microcracks. Hence, the mechanical and endurance properties of GO concrete were significantly improved after salt-freezing.
\end{abstract}

\section{Introduction}

In severe cold areas of the north, under the combined effect of chlorine salt and freeze-thaw, the surfaces of most concrete structures (bridges, airports, and anticollision walls) get seriously denuded. This phenomenon reduces the durability of these structures, increases the maintenance cost, and causes a huge economic loss $[1,2]$. Therefore, ensuring the durability of these structures in such salt-frozen environments has become the main research focus for scientists.

Generally, two common technical measures are adopted to improve the durability of concrete under such saltfreezing environment: (i) the use of a reasonable sand ratio, the introduction of air-entraining agents and mineral admixtures, and the reduction of the water-cement ratio [3-6] and (ii) waterproofing and sealing of the concrete surface [7-9]. In recent years, nanomaterials, due to their unique small size and interface and quantum effects, are incorporated into cement-based materials to improve the mechanical strength of concrete and make the microstructure more compact, reduce the penetration depth of chloride ions, and impede the corrosion of steel bars [10-13]. Graphene has attracted considerable scientific attention due to its large specific surface area, flexibility, and excellent mechanical properties. As an oxidation product of graphite, graphene oxide $(\mathrm{GO})$ contains different functional groups including hydroxyl, carboxyl, and epoxy; thus, it is easy for GO to disperse in water to form nanodispersed lamella [14]. $\mathrm{Lu}$ and Jia [15] prepared GO nanolamellae by ultrasonic dispersion and found that the addition of GO improved the microstructure and mechanical properties of the cementbased material and made the cement matrix to form polyhedral crystals through interweaving and embedding. Lei and Ye [16] expressed that the microstructure 
mechanical properties and frost resistance of the recycled mortar mixed with $0.6 \%$ GO were significantly improved. Zhang Zirui and $\mathrm{Wu}$ [17] examined the mechanical properties and durability of a self-leveling mortar with different GO contents by preparing a GO dispersion of $7.4 \mathrm{~g} / \mathrm{L}$ concentration and found that GO dispersion regulated the hydration of cement and improved the durability and mechanical properties of the cement-based self-leveling material. Previous studies [18-20] advocate that the addition of GO to polymers, ceramics, and other matrix materials can greatly improve the strength and toughness of the matrix.

Although some progress has been made in the field of GO cement-based material research, the salt-freezing resistance of GO concrete has not yet been reported. Therefore, in the present paper, the mechanical properties and durability of GO concrete with different GO contents under the combined action of chlorine salt and freeze-thaw were studied, and salt-freezing resistance mechanism was explored by scanning electron microscopy (SEM), X-ray diffraction (XRD), and energy-dispersive spectroscopy (EDS).

\section{Experimental}

2.1. Raw Material. Analytically pure graphite (particle size $<10 \mu \mathrm{m})$, sodium nitrate $\left(\mathrm{NaNO}_{3}\right)$, concentrated sulfuric acid $(98 \%)$, potassium permanganate $\left(\mathrm{KMnO}_{4}\right)$, phosphate $\left(\mathrm{H}_{3} \mathrm{PO}_{4}\right)$, hydrogen peroxide $\left(\mathrm{H}_{2} \mathrm{O}_{2}\right)$, and hydrochloric acid $(\mathrm{HCl})$ were provided by Shenyang Chemical sample Co., Ltd. SPC-100 superplasticizer was produced by Liaoyang Cologne Company. Brown and yellow liquid, water reduction rate $=35 \%$ and solid content $=40 \%$, was used as the water reducer. The chemical composition of PO 42.5 Rordinary Portland cement is presented in Table 1.

\subsection{Preparation of Graphene Oxide Lamellar Dispersion.} The solution was stirred continuously in a $40^{\circ} \mathrm{C}$ water bath for $2 \mathrm{~h}$ until it turned into a viscous brown liquid. A total of $230 \mathrm{ml}$ distilled water was added to the solution and stirred for $0.5 \mathrm{~h}$ at $98^{\circ} \mathrm{C}$. The solution was then cooled to room temperature, and $50 \mathrm{ml} \mathrm{H}_{2} \mathrm{O}_{2}$, was added to it; consequently, the solution turned into a bright yellow liquid [21]. The assynthesized solution was centrifugally washed with $10 \% \mathrm{HCl}$ and distilled water until its $\mathrm{pH}$ value reached close to 7 . The obtained GO was dissolved in distilled water and treated by a $300 \mathrm{~W}$ ultrasonic cleaning machine for $60 \mathrm{~min}$. Finally, the aqueous dispersion of GO was prepared with a solid content of $5 \mathrm{mg} / \mathrm{ml}$, and its technical indices are presented in Table 2.

2.3. Specimen Preparation. Four different GO contents ( $0 \%$, $0.01 \%, 0.03 \%$, and $0.05 \%$ ) were used to prepare concrete specimens (marked as GO0, GO1, GO3, and GO5, respectively). Twelve box concrete specimens of size $100 \mathrm{~mm} \times 100 \mathrm{~mm} \times 400 \mathrm{~mm}$ (with three specimens in each group) were prepared, and they were used to determine the relative dynamic elastic modulus and mass loss of GO concrete during the rapid freeze-thaw cycle test. A total of 64 standard cubes of size $100 \mathrm{~mm} \times 100 \mathrm{~mm} \times 100 \mathrm{~mm}$ (with three specimens in each group) were also prepared, and they
Table 1: Chemical composition of Portland cement.

\begin{tabular}{lcccccc}
\hline Chemical composition & $\mathrm{CaO}$ & $\mathrm{SiO}_{2}$ & $\mathrm{Al}_{2} \mathrm{O}_{3}$ & $\mathrm{Fe}_{2} \mathrm{O}_{3}$ & $\mathrm{MgO}$ & $\mathrm{SO}_{3}$ \\
\hline Content (\%) & 59.31 & 21.90 & 6.26 & 3.79 & 1.63 & 2.41 \\
\hline
\end{tabular}

were used to determine the compressive strength and pore structure parameters of GO concrete. The mixing ratios of GO concrete are depicted in Table 3. In order to prevent the uneven dispersion of GO in cement, before pouring GO into concrete specimens, the graphene oxide dispersion solution was mixed evenly with water and a specified amount of water reducer was added to it. The as-prepared GO solution was then dispersed in an ultrasonic cleaning machine $(300 \mathrm{kHz})$ for $30 \mathrm{~min}$ and mixed evenly with cement and coarse and fine aggregates according to the JTG E30/2005 standard. The specimens were demoulded after $24 \mathrm{~h}$, and finally, the test was carried out after 28 days of maintenance in a standard maintenance box.

\subsection{Experimental Method}

(1) The rapid freeze-thaw test method was carried out according to the "GB/T50082-2009 standard" (a test method for long-term performance and durability of ordinary concrete). The salt freeze-thaw cycle test was executed in a TDR-16 rapid freeze-thaw tester produced by the Tianjin Port Source Test instrument Factory, and the relative dynamic elastic moduli of GO concrete under different salt-freezing cycles were measured by a DT-12 dynamic elastic modulus tester.

(2) The uniaxial compressive strength of GO concrete was measured by an electrohydraulic servo pressure testing machine equipped with a YAW-YAW2000 A $200 t$ microcomputer. The axial displacement control was adopted during the test, and a loading rate of $5 \mathrm{~mm} / \mathrm{min}$ was applied along the axial direction of the specimen until it ruptured.

(3) The pore structure parameters of GO concrete before and after salt freezing were measured by a MIC84001 hardened concrete pore analyzer.

(4) The dried GO sample was tested by a Nicolet 6700 Fourier-transform infrared spectrometer (Thermo Fisher, USA), and its mineral composition was determined by a D/max-2500PC automatic powder $\mathrm{X}$-ray diffractometer (Rigaku.). The morphologies of hydration products after salt freezing were analyzed by a $\$ 4800$ scanning electron microscope (Hitachi.). Before the test, the crushed sample was dried in a vacuum oven at $45 \pm 5^{\circ} \mathrm{C}$ for $5 \mathrm{~h}$. The suitable sample was selected and fixed on the circular metal base, and the SEM test was carried out after gold spraying.

\section{Results and Discussion}

3.1. Structural Characterization of Graphene Oxide. The FTIR spectra of GO and graphite are displayed in Figure 1, and it is noticeable that the FTIR spectrum of GO is different 
TABle 2: Dispersion indices of GO.

\begin{tabular}{lccccc}
\hline Name & $\mathrm{pH}$ & Thickness $(\mathrm{nm})$ & Single rate $(\%)$ & Oxygen content (\%) & Sulfur content $(\%)$ \\
\hline GO & 6.8 & $0.05-1.0$ & $\geq 99$ & $\leq 49$ & $\leq 3$ \\
\hline
\end{tabular}

TABle 3: Mixing proportions of GO concrete $\left(\mathrm{kg} / \mathrm{m}^{3}\right)$.

\begin{tabular}{lcccccc}
\hline Number & Cement & Water & Sand & Stone & GO & PC \\
\hline GO0 & 420 & 168 & 782 & 1080 & 0 & 2.1 \\
GO1 & 420 & 168 & 782 & 1080 & 0.042 & 2.1 \\
GO3 & 420 & 168 & 782 & 1080 & 0.126 & 2.1 \\
GO5 & 420 & 168 & 782 & 1080 & 0.210 & 2.1 \\
\hline
\end{tabular}

from that of graphite. Due to the compact aggregation, large thickness, and weak light transmittance of graphite lamellae, the weak absorption of $\mathrm{C}=\mathrm{C}$ and carbonyl $(\mathrm{C}=\mathrm{O})$ appeared in the FTIR spectrum of graphite. In the FTIR spectrum of $\mathrm{GO}$, the stretching vibration absorption peaks of $\mathrm{O}-\mathrm{H}, \mathrm{C}=\mathrm{O}$, and $\mathrm{C}=\mathrm{C}$ appeared at $3420.25 \mathrm{~cm}^{-1}, 1733.20 \mathrm{~cm}^{-1}$, and $1621 \mathrm{~cm}^{-1}$, respectively. Moreover, the absorption peaks of C-O-C were observed at $1507.53 \mathrm{~cm}^{-1}, 1384.45 \mathrm{~cm}^{-1}$, $1224.44 \mathrm{~cm}^{-1}$, and $1052.66 \mathrm{~cm}^{-1}$. Therefore, it can be inferred that GO contained different functional groups, such as hydroxyl, carboxyl, and epoxy.

The XRD patterns of GO and graphite are presented in Figure 2, and it is evident that the characteristic peaks of GO are different from those of graphite. The peaks near $D_{f_{c}}=$ $\left(1-\left(f_{c n} / f_{c 0}\right)\right) \times 100 \% \quad$ (Figure $\left.2(\mathrm{a})\right) \quad$ and $D_{f_{c}}=\left(1-\left(f_{c n} / f_{c 0}\right)\right) \times 100 \%$ (Figure 3(b)) are the characteristic peaks of $\mathrm{GO}$ and graphite, respectively. The spacing of GO sheets increased from $3.61 \mathrm{~nm}$ to $8.32 \mathrm{~nm}$, as the oxidation of graphite introduced an oxygen-containing group to weaken the van der Waals force between the layers. After ultrasonic dispersion treatment, GO layers became separated and, in turn, the layer spacing became larger.

\subsection{Macroscopic Deterioration Characteristics of Salt-Frozen} Cyclic Specimen. As concrete is a heterogeneous composite material, its salt-freezing damage deterioration characteristics are closely related to microspores and microcracks. After the salt-freezing test, it was found that the deterioration of GO concrete occurred under a combination of different modes, such as mortar shedding, microcrack expansion, denudation, and massive shedding. After 50 saltfreezing cycles, fine particles of cement slurry (size $=2$ $3 \mathrm{~mm}$ ) fell off from the surface of each specimen until the surface floating slurry fell off in a large area. After 100 saltfreezing cycles, the surface of the specimen became rough due to the existence of fine aggregates, and the intensity of denudation increased further. Shedding occurred at local edges and corners, coarse aggregates started to appear, and a small crack appeared at the junction of coarse and fine aggregates. After 150 salt-freezing cycles, the loss of cementitious material on the specimen surface was serious, fine and coarse aggregates gradually fell off, particles became larger (of a size of few centimeters), and the number of internal microcracks and pores increased. After 200 saltfreezing cycles, a large amount of coarse aggregate appeared

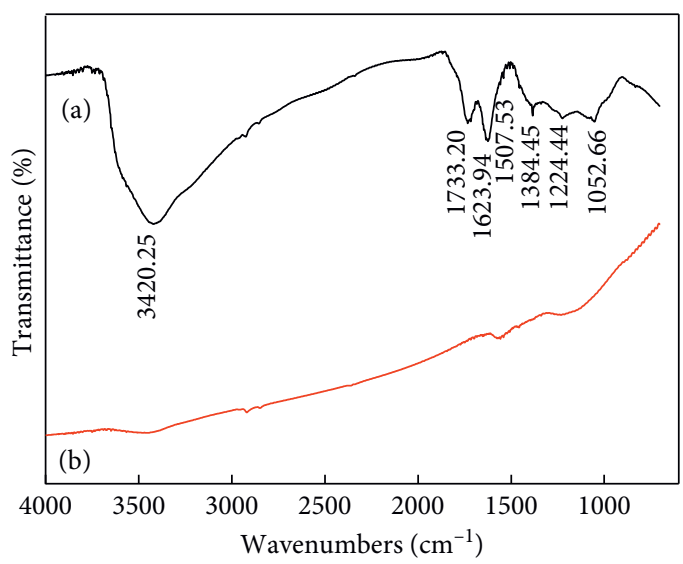

(a) Graphite oxide

(b) Graphite

FIGURE 1: FTIR spectra of GO and graphite.

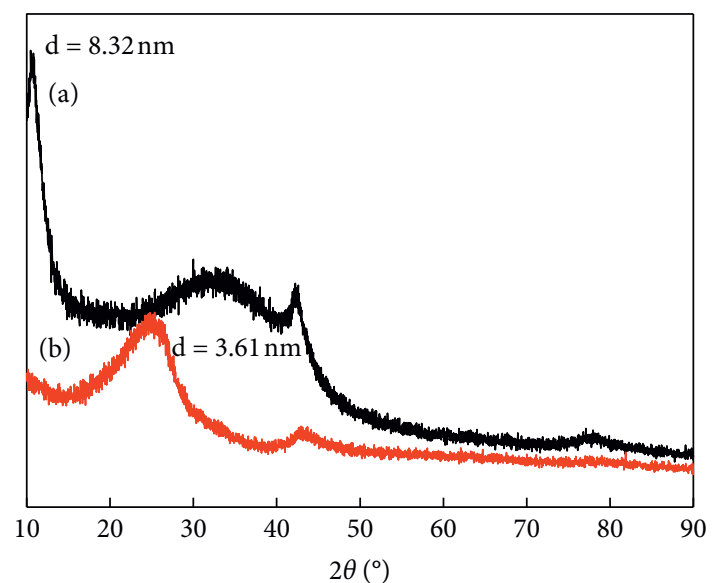

(a) Graphite oxide

(b) Graphite

FIGURE 2: XRD patterns of GO and graphite.

on the specimen surface, the loss of cementitious material became severe, edges and corners were partially dropped, the structure became brittle and loose, the bonding force at the junction of coarse and fine aggregates became weak, and the salt-freezing damage was serious.

The appearances of GO concrete after different saltfreezing times are displayed in Figure 3. After 200 saltfreezing cycles, a large amount of coarse aggregate appeared on the concrete specimen surface with $0 \%, 0.01 \%$, and $0.05 \%$ $\mathrm{GO}$, the cementitious material was lost, the surface was uneven, and an obvious drop block appeared at the lower left corner of the specimen. However, for the concrete specimen with $0.03 \% \mathrm{GO}$, very few freeze pits and coarse aggregates 


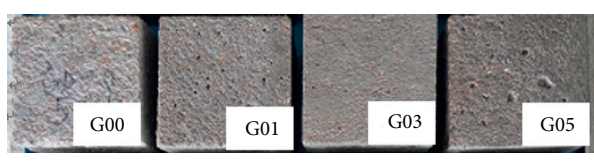

(a)

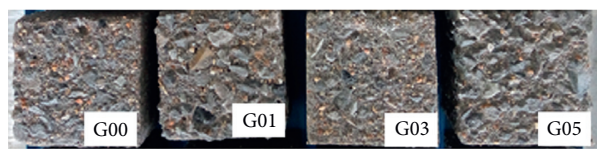

(c)

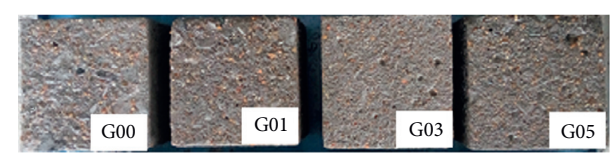

(b)

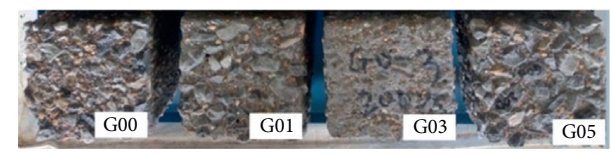

(d)

Figure 3: Macroscopic failure characteristics of GO concrete under different salt-freezing cycles. (a) 50 salt-freezing cycles. (b) 100 saltfreezing cycles. (c) 150 salt-freezing cycles. (d) 200 salt-freezing cycles.

appeared on the surface, less falling blocks existed at the edges, and no peeling phenomenon occurred at the junction of coarse and fine aggregates. Therefore, the concrete had the best salt-freezing resistance for the GO content of $0.03 \%$.

\subsection{Mechanical Properties of Salt-Frozen Cyclic Specimen.} After the salt-freezing process, the internal pore structure of GO concrete changed greatly, and new cracks appeared, thus causing a change in its mechanical properties. In order to study the effects of different salt-freezing cycles on the mechanical properties of GO concrete, the compressive strength loss rates of GO concrete specimens after different salt-freezing cycles were calculated by

$$
D_{f c}=\left(1-\frac{f_{c n}}{f_{c 0}}\right) \times 100 \%,
$$

where $D_{f_{c}}$ is the compressive strength loss rate of GO concrete after salt-freezing (\%), $f_{c n}$ is the compressive strength of GO concrete after $n$ number of salt-freezing cycles $(\mathrm{MPa})$, and $f_{c 0}$ is the compressive strength of GO concrete before salt-freezing $(\mathrm{MPa})$.

The variation trends of the compressive strengths of GO concrete specimens under different salt-freezing cycles are displayed in Figure 4. Before salt-freezing, the addition of an appropriate amount of GO improved the compressive strength of the concrete. The $0.03 \%$ GO concrete had the highest compressive strength $(14.01 \%$ higher than that of the specimen without GO). When $0.05 \%$ GO was added, the compressive strength of the concrete decreased significantly. The appropriate amount of GO increased the chemical water binding capacity in the cement slurry, promoted hydration reactions, formed a hydrated calcium silicate gel, and improved the compressive strength of the concrete. However, when the GO content was too large, it could not be well dispersed in the concrete due to the enrichment of $\mathrm{C}$, thus resulting in a decrease in the compressive strength. After the salt-freezing process, the compressive strength of GO concrete decreased. In comparison to the ordinary specimen, the compressive strength of GO concrete was improved after salt-freezing. The $0.03 \%$ GO concrete had the best compressive strength, and it experienced the lowest compressive strength loss rate after 200 salt-freezing cycles. Therefore, the addition of $0.03 \%$ GO significantly reduced the damage of the concrete during salt-freezing [22].
3.4. Mass Losses and Relative Dynamic Elastic Moduli of SaltFrozen Cyclic Specimens. During salt-freezing, microcracks and voids in GO concrete expanded with the increasing saltfreezing time; this phenomenon led to varying degrees of denudation and changed the surface quality of concrete specimens. In order to examine the surface qualities of GO concrete specimens after different salt-freezing cycles, their mass loss rates were calculated by

$$
D_{g}=\left(1-\frac{m_{g n}}{m_{g 0}}\right) \times 100 \%,
$$

where $D_{g}$ is the mass loss rate of the specimen during the salt-freezing (\%), $m_{g n}$ is the mass of the specimen after $n$ number of salt-freezing cycles $(\mathrm{kg})$, and $m_{g 0}$ is the mass of the specimen before salt-freezing $(\mathrm{kg})$.

The changes in the mass loss rates of GO concrete specimens during salt-freezing are presented in Figure 5. It is clear that the mass loss rate of GO concrete increased with the increasing salt-freezing time. The denudation intensity of each concrete specimen was similar in the early stage of saltfreezing. After 100 salt-freezing cycles, the rising trend of the mass loss rate curves accelerated, the spalling amount of the specimens increased, and the internal salt-freezing damage got intensified. During the 200th salt-freezing cycle, the masses of GO0, GO1, and GO5 specimens were about $94 \%$ of their initial masses, whereas the mass loss rate of GO3 was about $4.89 \%$, and the slope of its mass loss rate curve was lower than that of other specimens; hence, it implies that the mass loss rate of $0.03 \%$ GO concrete was the smallest, and its salt corrosion resistance was the best.

Figure 6 illustrates the variation trends of the relative dynamic elastic moduli of GO concrete specimens during salt-freezing. It is noticeable that the relative dynamic modulus of GO concrete decreased with the increasing saltfreezing time. In the early stage of salt-freezing, the relative dynamic elastic modulus of each GO concrete specimen decreased slowly, and their changing trends were the same. When the salt-freezing cycle was more than 75 times, the relative dynamic elastic modulus of the GO5 specimen decreased significantly. The decreasing trend of the relative dynamic elastic modulus of other specimens was GO0 $>$ GO1>GO3. At the 150th salt-freezing cycle, the relative dynamic elastic moduli of GO0 and GO1 were $62.97 \%$ and $66.1 \%$, respectively (these values are close to the 


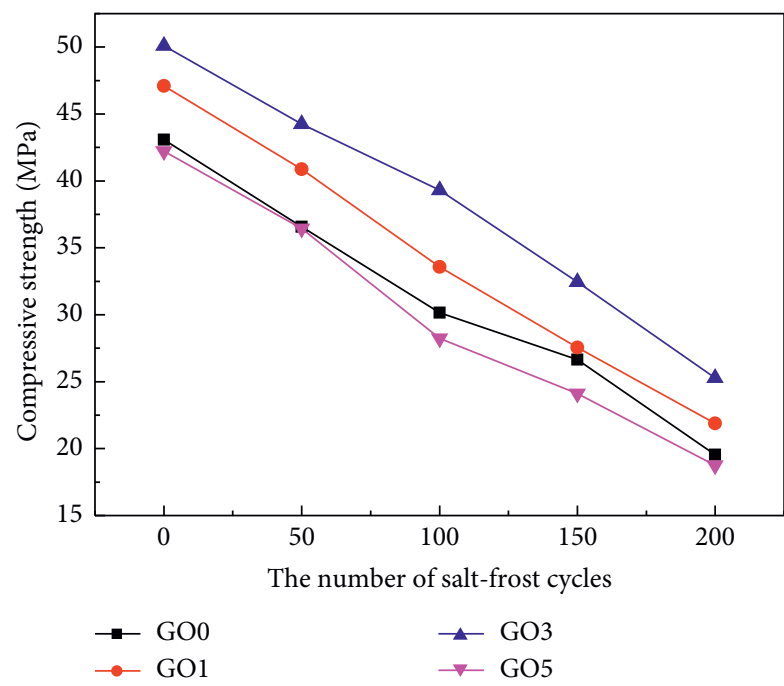

(a)

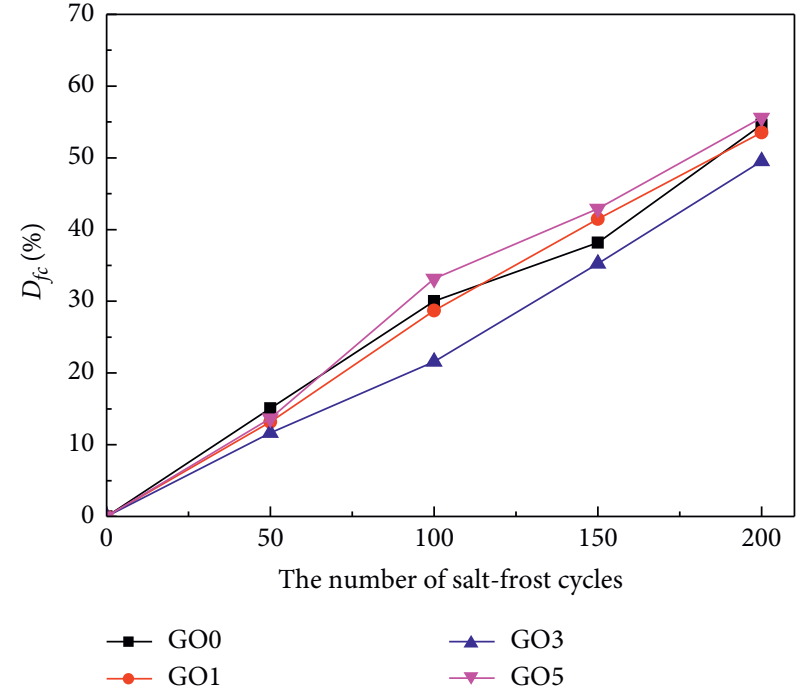

(b)

FIGURE 4: Relationship between the compressive strength of GO concrete and the number of salt-freezing cycles. (a) Relationship between salt-frost cycles and the compressive strength. (b) Relationship between salt-frost cycles and $\mathrm{D}_{\mathrm{fc}}$.

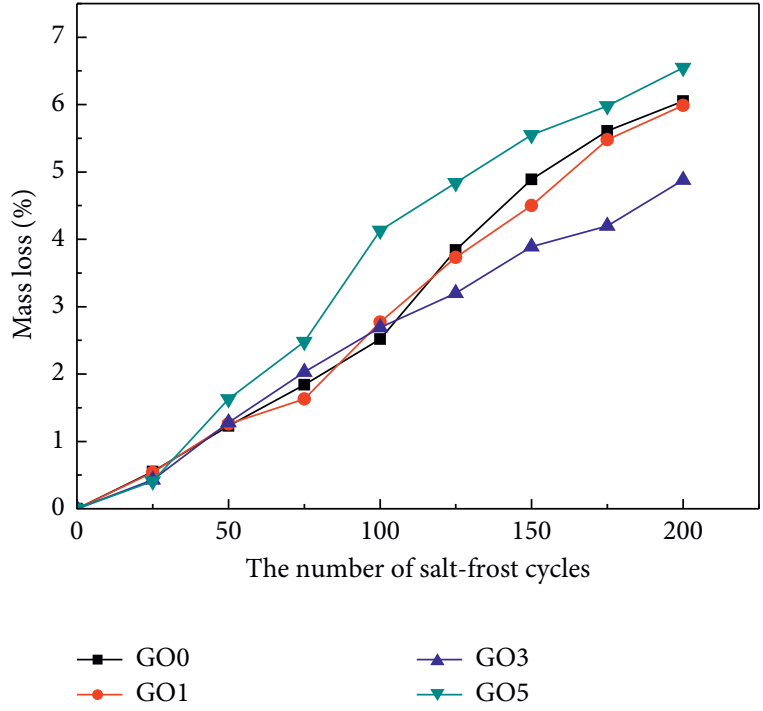

Figure 5: Mass loss rates of concrete under different salt-freezing cycles.

benchmark state of concrete failure), and the GO5 specimen ruptured. At the 200th salt-freezing cycle, the relative dynamic elastic modulus of GO3 was $60.95 \%$, which is close to the standard failure state.

3.5. Bubble Characteristic Parameters of Salt-Frozen Cyclic Specimens. In order to study the effects of different saltfreezing cycles on the microscopic properties of GO concrete, the air contents in GO concrete specimens after saltfreezing were calculated by

$$
A=\frac{\sum l}{T}
$$

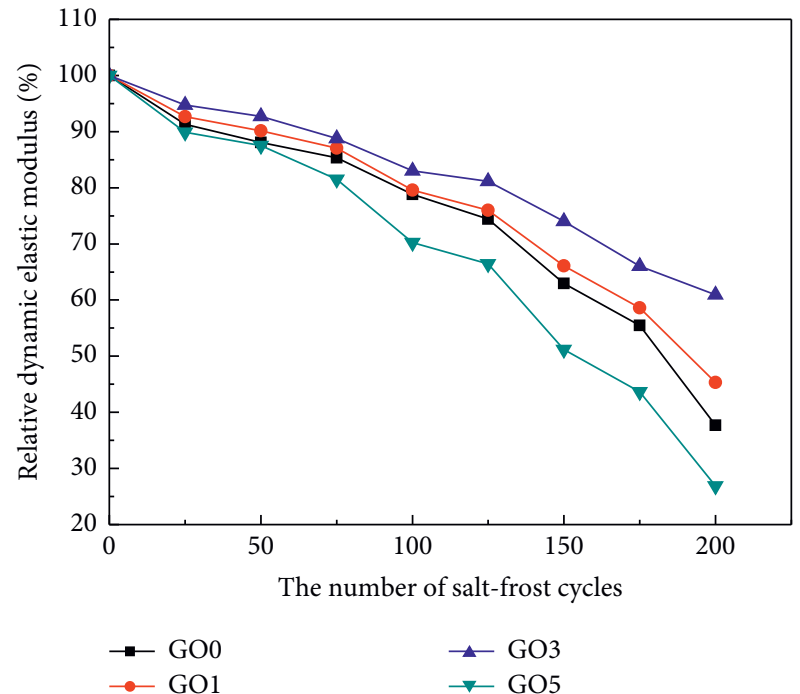

FIgURE 6: Dynamic elastic moduli of concrete under different saltfreezing cycles.

where $A$ is the air content of in GO concrete specimens after salt-freezing cycle (\%); $\sum l$ is the sum of the lengths of bubble strings cut across the wire $(\mathrm{mm})$; Tis the cable length $(\mathrm{mm})$.

The air contents and bubble spacing coefficients of GO concrete specimens before and after salt-freezing are presented in Figures 7 and 8, respectively. After 100 saltfreezing cycles, the air content in GO concrete increased, whereas the bubble spacing coefficient decreased due to two main reasons: (i) with the prolonged salt-freezing time, cracks appeared due to the frost heave pressure and increased the pore volume and (ii) during salt-freezing, ions in the pore solution migrated under the thermal stress and contacted with microcracks, thus causing a reduction of the bubble spacing coefficient. 


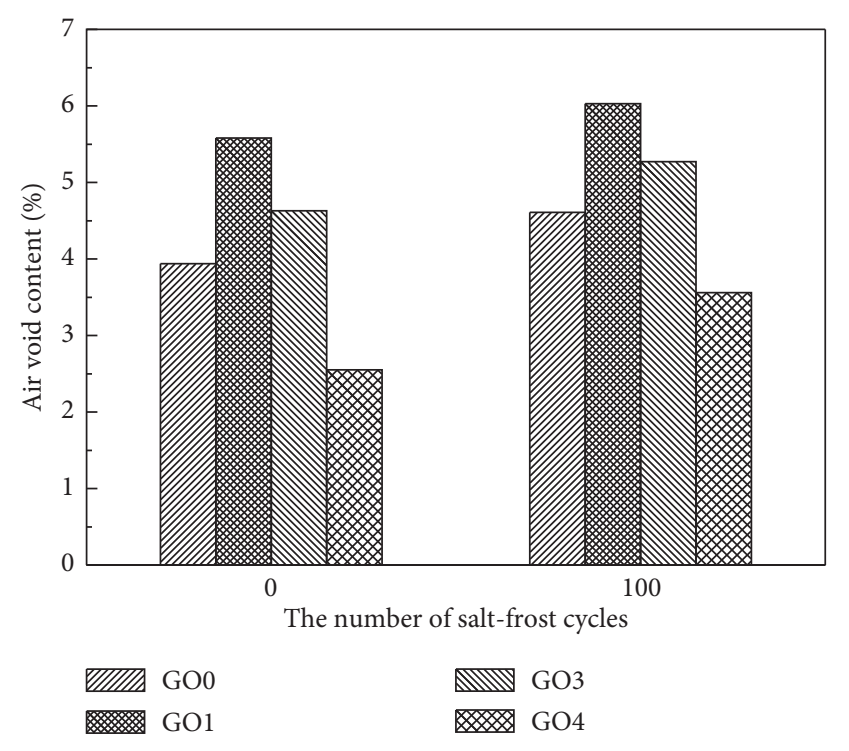

FIgURe 7: Air contents of GO concrete.

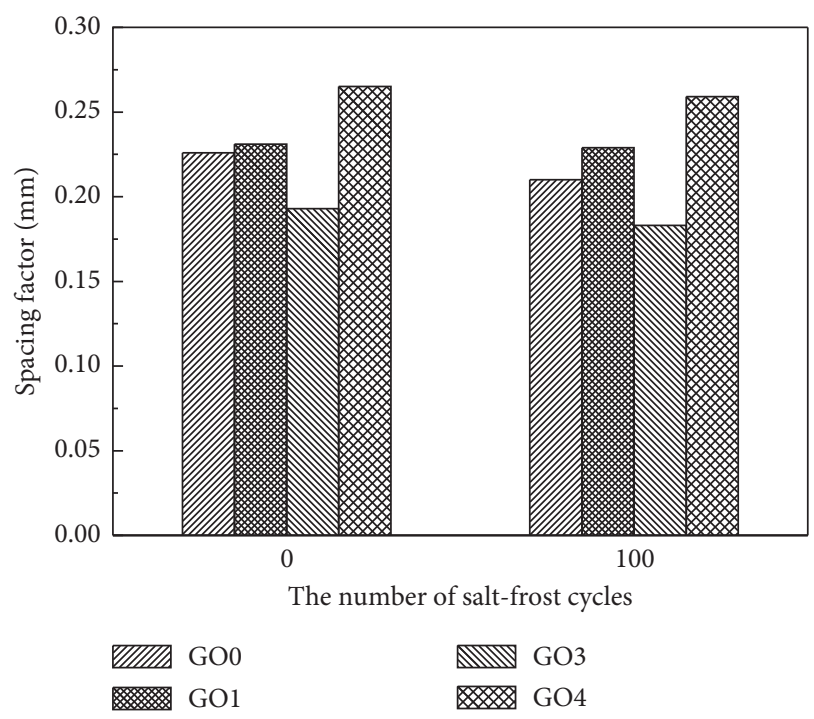

Figure 8: Bubble spacing coefficients of GO concrete.

Figures 9 and 10 display the microscopic bubble imaging of GO concrete after 100 salt-freezing cycles. Bubbles in the GO3 specimen were smaller and more closely arranged, whereas bubbles in the GO0 specimen were relatively large and sparsely arranged. The bubble spacing coefficients of GO0 and GO3 after 100 saltfreezing cycles were measured as $0.210 \mathrm{~mm}$ and $0.183 \mathrm{~mm}$, respectively; therefore, the bubble spacing coefficient of GO0 was $13 \%$ greater than that of GO3; it indicates that the frost resistance of GO0 was poorer than that of GO3. After 200 salt-freezing cycles, the surface denudation of GO3 was small, and its relative dynamic elastic modulus was the largest. Therefore, the addition of an appropriate amount of GO changed the microstructure and pore parameters of concrete and improved the salt-freezing resistance.

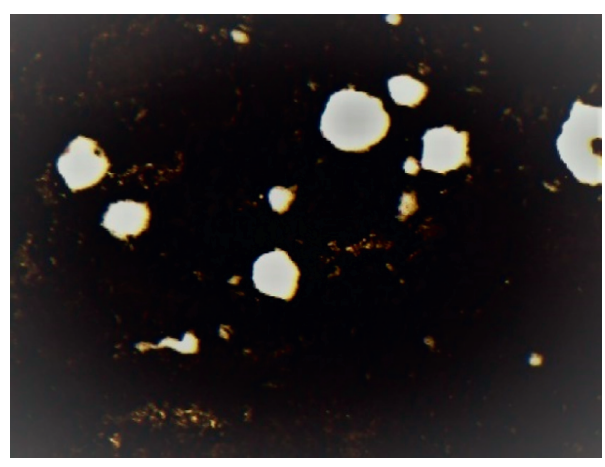

Figure 9: Bubble imaging of GO3 after 100 salt-frost cycles.

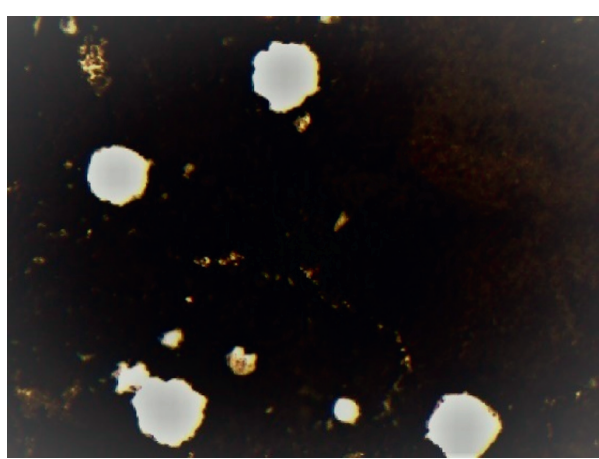

Figure 10: Bubble imaging of GO0 after 100 salt-frost cycles.

3.6. Microstructure after Salt-Freezing. In order to analyze the microstructures of GO concrete specimens under the combined effect of freeze-thaw and chloride salt, the specimens before and after salt-freezing were taken out, and cubic pieces of size $1 \mathrm{~cm} \times 1 \mathrm{~cm} \times 1 \mathrm{~cm}$ were selected in the range of $10-15 \mathrm{~mm}$ at the bottom to spray gold on the surface of the specimens. SEM and EDS tests were then performed, and the detected structures are displayed in Figures 11-13. The internal micromorphologies of the reference specimen and the $0.03 \%$ GO specimen before and after salt-freezing are exhibited in Figure 11. Before salt freezing, the hydration products of GO concrete existed between the pores of the matrix, and the existence of very few internal cracks made the microstructure more compact. After 100 salt-freezing cycles, the concrete surface became brittle and loose. Voids in the GOO specimen became larger, the microstructure was reticular, and the $\mathrm{C}-\mathrm{S}-\mathrm{H}$ gel structure and the $\mathrm{CH}$ crystal ruptured. Very few internal pores appeared in GO3, and a relatively dense layered microstructure was formed. After 200 saltfreezing cycles, the surface denudation of the concrete got intensified, the bonding force at the junction of aggregates became weak, and the structure became more brittle. Microcracks in the GO0 specimen grew and propagated until coarse aggregates flaked along the matrix. Fewer microcracks were formed in GO3, and the degree of denudation increased, thus leading to the increase of pores, the interweaving and superposition of surrounding structures, and the compactness of the microstructure. Therefore, the addition of an appropriate amount of GO 


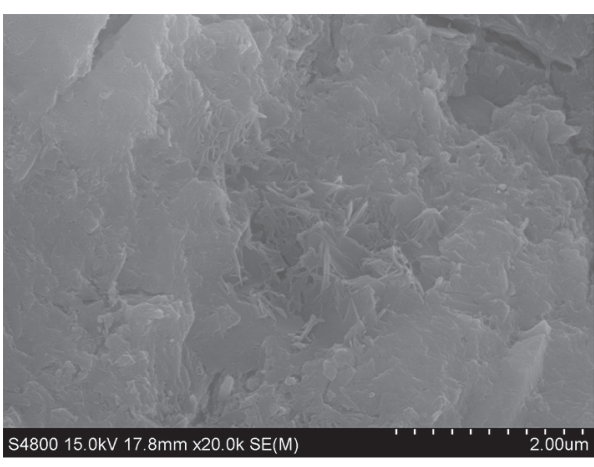

(a)

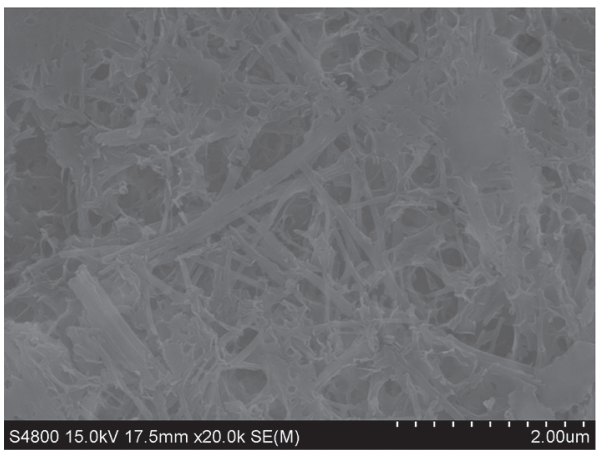

(c)

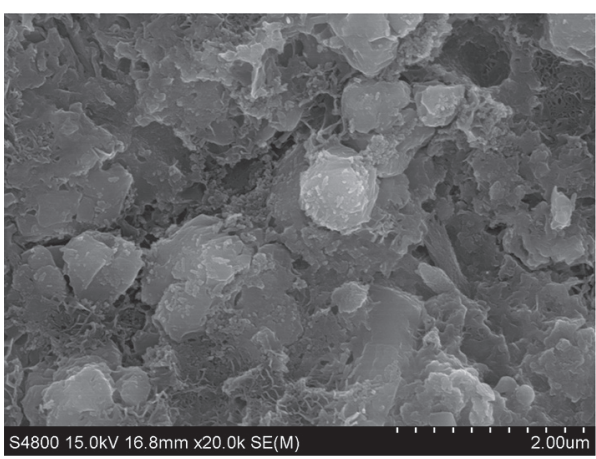

(e)

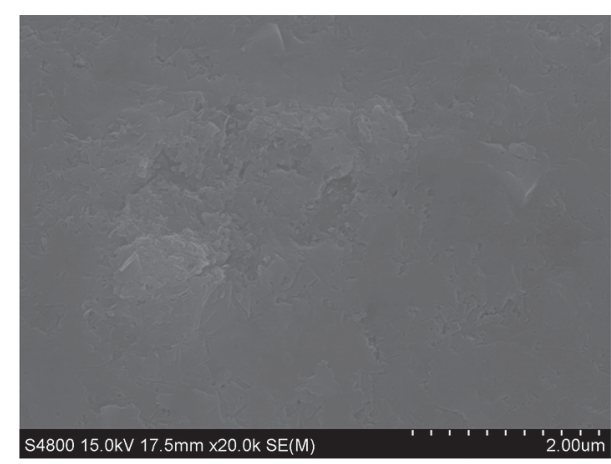

(b)

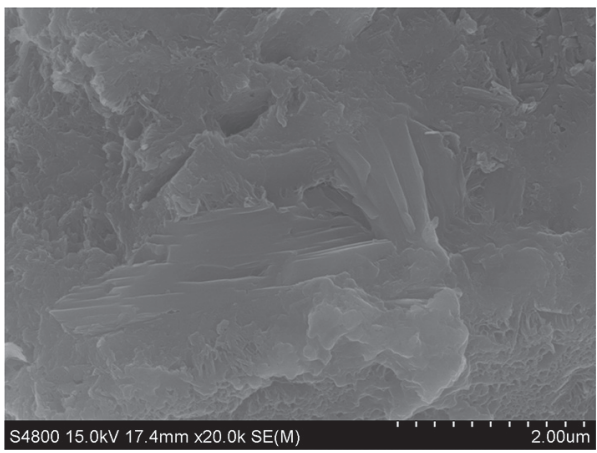

(d)

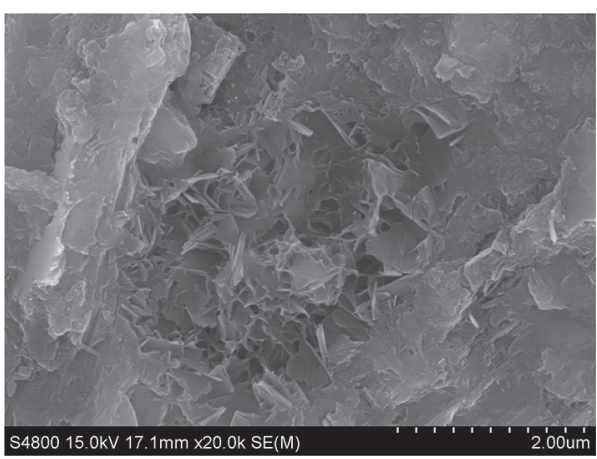

(f)

Figure 11: Microstructures of GO concrete before and after different salt-frost cycles. (a) GO0 after 0 salt-freezing cycles (b) GO3 after 0 salt-freezing cycles. (c) GO0 after 100 salt-freezing cycles. (d) GO3 after 100 salt-freezing cycles. (e) GO0 after 200 salt-freezing cycles. (f) GO3 after 200 salt-freezing cycles.

effectively hindered the damage of concrete micromorphology and slowed down the initiation and propagation of internal microcracks during salt-freezing.

The EDS spectra of the reference specimen and the $0.03 \%$ GO specimen after 100 salt-freezing cycles are presented in Figures 12 and 13, respectively. It is noticeable that the amount of $\mathrm{C}$ in the GO3 specimen was higher than that in the reference specimen. It happened because the addition of an appropriate amount of GO regulated the hydration of cement, promoted the formation of hydration products, and arranged the crystal in an orderly manner to form a regular and dense microstructure.

\subsection{Mechanism of Improving the Salt-Freezing Resistance of} GO Concrete. The XRD patterns of hydration products in the matrix of GO concrete after 200 salt-freezing cycles are exhibited in Figure 14. By comparing the diffraction peaks of $\mathrm{CH}$ crystal and $\mathrm{C}-\mathrm{S}-\mathrm{H}$ gel in the specimens with different $\mathrm{GO}$ contents, it is clear that the diffraction intensity of $\mathrm{CH}$ crystal decreased with the increasing GO content, whereas the diffraction peak of $\mathrm{C}-\mathrm{S}-\mathrm{H}$ gel first increased and then decreased. It implies that the addition of an appropriate amount of $\mathrm{GO}$ restricted the content of $\mathrm{CH}$ to a certain extent. Thus, a large part of $\mathrm{CH}$ crystal was transformed into other crystals during cement hydration. Consequently, a large amount of $\mathrm{C}-\mathrm{S}-\mathrm{H}$ gel was formed and the microstructure of the cement matrix became more compact.

The SEM morphologies before and after salt-freezing and the XRD patterns after salt-freezing reveal that the 


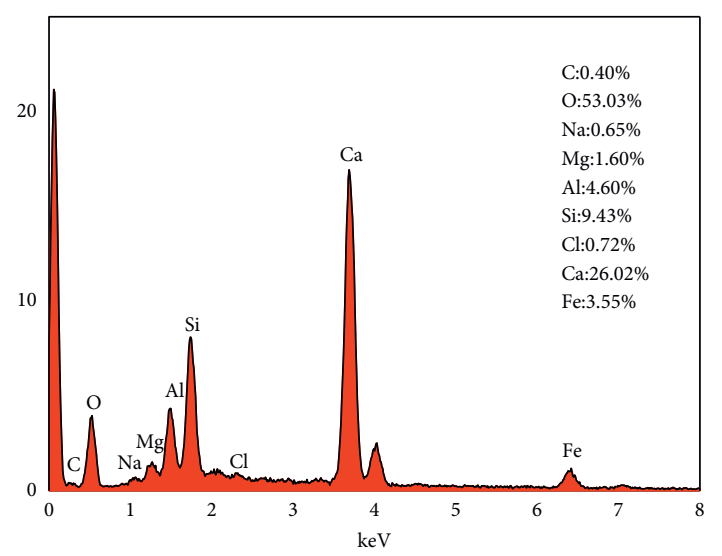

FIgURE 12: EDS spectrum of GO0 after 100 salt-frost cycles.

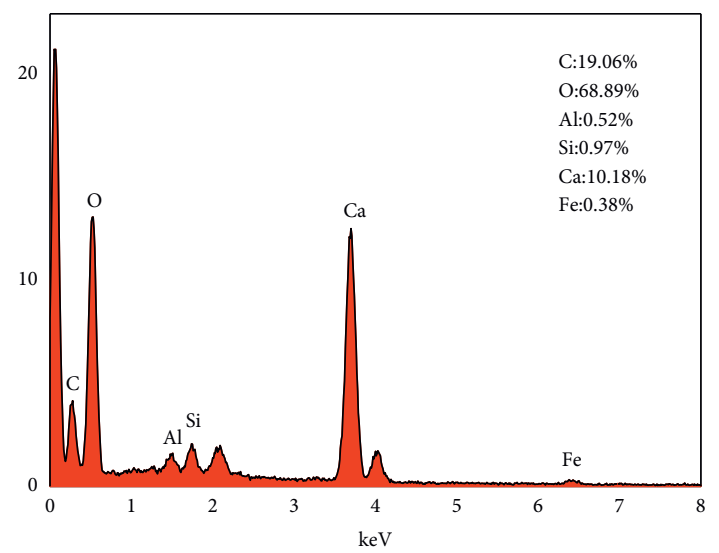

FIgURE 13: EDS spectrum of GO3 after 100 salt-frost cycles.

hydration product of GO0 (C-S-H) was loose; thus, it facilitated the growth of $\mathrm{CH}$ crystal and simultaneously limited the growth of $\mathrm{C}-\mathrm{S}-\mathrm{H}$ gel. With the prolonged saltfreezing time, cracks started to appear in the microstructure and, in turn, the salt solution infiltrated into the matrix to reach the saturation state. During salt-freezing, the cracking and expansion of microcracks easily occurred in the inner matrix, and this phenomenon increased the degree of salt-freezing damage. The $\mathrm{C}-\mathrm{S}-\mathrm{H}$ gel in $\mathrm{GO} 3$ became intertwined to form polyhedral hydrated crystals. Thus, the microstructure became more compact, regular, and orderly, and the number of pores was reduced. The addition of $0.03 \%$ GO regulated the microstructure of the cement matrix, promoted the hydration of cement, and formed more $\mathrm{C}-\mathrm{S}-\mathrm{H}$ gel structures to wrap the $\mathrm{CH}$ crystal; hence, the crystallization was controlled in a suitable state, the microstructure of the matrix became more uniform and dense, and the infiltration of the salt solution was reduced. During salt-freezing, the frost heave pressure in the matrix decreased, and the degree of salt-freezing damage was reduced. Therefore, the addition of an appropriate amount of GO improved the microstructure and salt-freezing resistance of concrete.

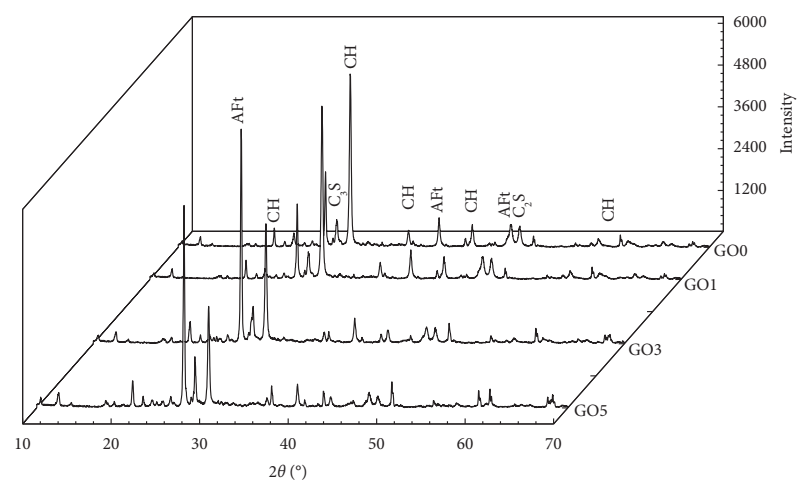

FIGURE 14: XRD patterns of GO concrete.

\section{Conclusion}

(1) The best compressive strength of GO concrete was achieved with the optimum GO content of $0.03 \%$. After 200 salt-freezing cycles, the loss rate of compressive strength and the amount of denudation were found to be the smallest. When the GO content was greater than $0.03 \%$, the resistance of GO concrete to salt and frost became worse.

(2) The SEM analysis revealed that the optimum GO content regulated the microstructure and pore parameters of concrete, thereby making the microstructure more compact and preventing the corrosion and damage of GO concrete in the salt solution by improving its salt-freezing resistance.

(3) The XRD analysis indicated that the optimum GO content promoted the hydration of cement, produced a large number of $\mathrm{C}-\mathrm{S}-\mathrm{H}$ gel structure, effectively hindered the destruction of concrete micromorphology during salt freezing, and slowed down the initiation and propagation of internal microcracks. Thus, the mechanical and corrosion properties of GO concrete were significantly improved after salt-freezing

\section{Data Availability}

The data used to support the findings of this study are available from the corresponding author upon request.

\section{Conflicts of Interest}

The authors declare that they have no conflicts of interest.

\section{Acknowledgments}

The authors acknowledge the support of the National Natural Science Foundation of China (Grant no. 51578099).

\section{References}

[1] L. C. Hao and Y. Z. Liu, "Durability of thermal insulation concrete under coupled action of chloride salt erosion and freeze-thaw cycles," Journal of Guangxi University (Nat Sci Ed), vol. 43, no. 04, pp. 1562-1568, 2018. 
[2] A. Sagüés, Effect of localized corrosion of steel on chlorideinduced concrete cover cracking in reinforced concrete structures, University of South Florida, Tampa, FL, USA, Ph.D, 2013.

[3] J. J. Valenza and G. W. Scherer, "A review of salt scaling: I. Phenomenology," Cement and Concrete Research, vol. 37, no. 7, pp. 1007-1021, 2007.

[4] W. LI, M. Pour-Ghaz, J. Castro, and J. Weiss, "Water absorption and critical degree of saturation relating to freezethaw damage in concrete pavement joints," Journal of $M a-$ terials in Civil Engineering, vol. 24, no. 3, pp. 299-307, 2012.

[5] X. P. Su and Q. Wang, "Corrosion damage of concrete under multi-salt soaking freezing-thawing and dry-wet cycles," Journal of Jilin University (Engineering and Technology Edition), vol. 45, no. 1, pp. 112-120, 2015.

[6] G. Liu, "Influence of different water-cement ratio on the properties of concrete with manufactured-sand in severe environment," Concrete, no. 10, pp. 44-51, 2015.

[7] A. A. Almusallam, F. M. Khan, S. U. Dulaijan et al., "Effectiveness of surface coatings in improving concrete durability," Cement \& Concrete Composites, vol. 25, no. 5, pp. 473-481, 2003.

[8] M. Delucchi, A. Barbucci, and G. Cerisola, "Study of the physico-chemical properties oforganic coatings for concrete degradation control," Construction and Building Materials, vol. 11, no. 7-8, pp. 365-371, 1997.

[9] C. M. Hansson, L. Mammoliti, and B. B. Hope, "Corrosion inhibitors in concrete-part I: the principles," Cement and Concrete Research, vol. 28, no. 12, pp. 1775-1781, 1998.

[10] G. Y. Han, "Research progress nanomaterials applicat ion in concrete," Concrete, no. 7, pp. 65-68, 2018.

[11] J. Chen, S. Kou, and C. Poon, "Hydration and properties of nano-TiO2 blended cement composites," Cement and Concrete Composites, vol. 36, no. 5, pp. 838-844, 2012.

[12] M. Zhangp and Z. He, "Application and research progress of nano-titanium dioxide in the field of cement-based materials," Bulletin of the Chinese Ceramic Society, vol. 37, no. 3, pp. 894-902, 2018.

[13] A. S. Faizuddin and W. M. s. Supit, "Chloride induced corrosion durability of high volume fly ash concretes containing nano particles," Construction and Building Materials, vol. 99, pp. 205-225, 2015.

[14] X. Du, I. Skachko, A. Barker, and E. Y. Andrei, "Approaching ballistic transport in suspended graphene," Nature Nanotechnology, vol. 3, no. 8, pp. 491-495, 2008.

[15] S. H. Lv and C. M. Jia, "Regulation of graphene oxide on cement hydration products and their aggregates," Fine Chemicals, vol. 34, no. 05, pp. 576-581+600, 2017.

[16] B. Lei and Y. M. Ye, "Experimental study on the mechanical properties of recycled mortar with graphene oxide," Journal of Nanchang Universit (Natural Science), vol. 42, no. 1, pp. 2432, 2018.

[17] Z. R. Zhang and J. D. Wu, "Effect of graphene oxide on properties of cement-based self-leveling mortar," Materials Reports, vol. 33, no. 2, pp. 240-245, 2019.

[18] W. J. Cui, J. Chen, C. Xie et al., "Preparation and properties of sodium polyacrylate/graphene oxide composites," Carbon, no. 1, pp. 13-17, 2012.

[19] Z. Pan, W. H. Duan, and D. Li, Graphene Oxide Reinforced Cement and Concrete, WO, San Francisco, CA, USA, US Patent2013096990 Al, 2013.

[20] T. Kuila, S. Bose, C. E. Hong et al., "Preparation of functionalized graphene/linear low density polyethylene composites by a solution mixing method," Carbon, vol. 49 , no. 3 , pp. 1033-1037, 2011.
[21] T. Du, Effect Of Grapheme Oxide on Properties of CementBased Composite, HarbinInstitute of Technology, 2014.

[22] A. Mohammed, J. G. Sanjayan, W. H. Duan, and A. Nazari, "Graphene oxide impact on hardened cement expressed in enhanced freeze-thaw resistance (Article)," Journal of Materials in Civil Engineering, vol. 28, no. 9, 2016. 